MATHEMATICAL ASSOCIATION

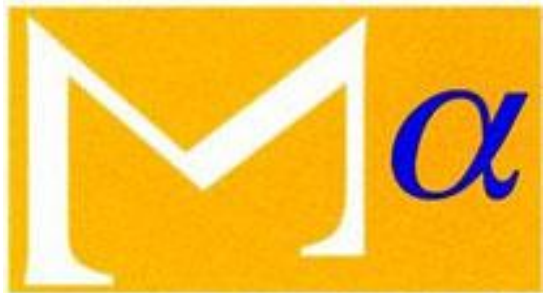

supporting mathematics in education

The Teaching of Mathematics and Physics

Author(s): C. S. Jackson

Source: The Mathematical Gazette, Vol. 3, No. 47 (Oct., 1904), pp. 75-78

Published by: Mathematical Association

Stable URL: http://www.jstor.org/stable/3603631

Accessed: 21-12-2015 02:49 UTC

Your use of the JSTOR archive indicates your acceptance of the Terms \& Conditions of Use, available at http://www.jstor.org/page/ info/about/policies/terms.jsp

JSTOR is a not-for-profit service that helps scholars, researchers, and students discover, use, and build upon a wide range of content in a trusted digital archive. We use information technology and tools to increase productivity and facilitate new forms of scholarship. For more information about JSTOR, please contact support@jstor.org. 
works for Nature (vols. 67, 68, 69) and the Mathematical Gazette. He had fivished a treatise on "Kummer's Quartic Surface," which will be published by the Cambridge University Press. He had just commenced a book on Analytical Geometry, and had been requested to write another on Elementary Pure Geometry, which it was hoped he would undertake later.

Ronald Hudson's was a singularly strong, noble and lovable personality. The writer of this note was attached to him by long and intimate friendship, and experienced many an act of thoughtful kindness at his hands. It is impossible to write of him anything but a bare record while the thought of his death is so near and overwhelming. We can scarcely yet realise that one who was so clearly destined to win fame if he had lived has already gone from us.

F. S. M.

\section{THE TEACHING OF MATHEMATICS AND PHYSICS.*}

The Association of Public School Science Masters fixed their annual meeting for Jan. 16, and accepted a proposal by Mr. R. H. Thwaites to read a paper for discussion at that meeting on the subject of the possible fusion of the teaching of mathematics and science in public schools. I wrote to Mr. Pendlebury, pointing out the interest of the subject to us, and suggesting that our meetings ought not to clash. In reply, he requested me to open a similar discussion at our meeting to-day. I hope I have made it clear that the suggestion that the subject is ripe for consideration is originally due to $\mathrm{Mr}$. Thwaites.

As some of us were present last week at the Science meeting; and as the discussion there has been fully reported, I have taken advantage of $\mathrm{Mr}$. Pendlebury's alternative permission to continue the discussion rather than to attempt any detailed account of what then took place. I am very conscious that $I$ am risking the commission of two grave errors-I may be preaching to the converted-and, even worse, I may appear to be trying to instruct those who know more about the matter in hand than I do myself. On these grounds I ask for your indulgence.

It seems to me that there are two main reasons why we who are as a body teachers of elementary mathematics should be glad to consider favourably any suggestion of the kind under discussion. In the first place, there are signs that the true function of examinations is beginning to be more clearly realised. Recent events have been very gratifying to those of us who hold that the examiner is an excellent partner, but a very bad master, for the teacher. But with the decay and disappearance of the mechanical examination system there will pass away a powerful inducement to work and a bond of sympathy between the teacher and the pupil, who will no longer find themselves in alliance against their common enemy, the examiner. Failing the unhealthy stimulus of examination pressure, we shall have to do our utmost to develop and utilise the natural stimulus of keen interest in the subject.

The second reason to which I refer as supporting the introduction of experimental work is this. Professor Pascal has observed that the movement towards increased rigour of demonstration has led in almost all branches of mathematics to minute and critical discussions, in the course of

* A paper opening a discussion at the annual meeting of the Mathematical Association Jan. 23, 1904. 
which propositions, formerly treated as universal and almost axiomatic, have been shown to depend upon subtle and complex conditions. This has unquestionably created a good deal of embarrassment for teachers of elementary mathematics. It is impossible to impose rigour on the beginner, and most undesirable to attempt it. No less in authority than Professor Klein can be cited in support of this view, which, in fact, constitutes the principle underlying the recent reforms in the teaching of geometry.

Even at the Ecole Polytechnique, where the students can hardly be called beginners, the attempt which was made to treat the Calculus from the outset on lines of strict rigour, had, I am told, to be abandoned. No doubt in commencing the Calculus one nay now and again draw attention to some mathematical curiosity, such as that which Professor Pascal adopts as his first example :

$$
L_{t=0}^{t} \underset{n=\infty}{L^{t}} \frac{\sin ^{2}\left(x \cdot n^{\prime} \cdot \pi\right)}{t^{2}+\sin ^{2}\left(x \cdot n^{\prime} \cdot \pi\right)}
$$

which is zero when $x$ is commensurable and unity when $x$ is incommensurable. But if we are to put aside refinements which a beginner cannot appreciate, we shall find it very difficult to avoid enunciating theorems as generally true without regard to the qualifications under which alone they are true. In our difficulty we may turn for help to history. The evolution of the individual is a recapitulation of the evolution of the race. Now a science begins with facts and special methods, and ends with critical exactness and with generalised methods. As teachers of pre-university work, it is our nain business to familiarise our pupils with facts and the mode of dealing with facts.

To my mind, the due discrimination on broad lines between the work proper to a school and the work proper to a university is a problem which calls for our most serious attention, and the solution of which will dispose of many of our difficulties. As teachers of school work, we must frequently be content with the certainty that a method is available in a particular case. Thus I should advocate the use of the method of differentiation in obtaining particular expansions, whose convergency may be examined in each individual case rather than purporting to furnish any general method of expanding functions. We shall have to lay increased stress on intuition. With that tendency to fetishism which most of us inherit, we have been sometimes apt to unconsciously attribute a sort of objective value to certain "pieces of book-work." To reproduce Duchayla's proof was to perform a meritorious action.

Under the influence of Mach we have come to doubt the objective value of this or any similar performance, and to consider rather whether the "proof" has really helped the student to realise more vividly, distinctly, and precisely that the proposition is true. Has it aided him to form a useful 'concept'?

It must, of course, be acknowledged that the truth and beauty of a demonstration may flash upon the mind after, but not until after, long study: But these matters are not for the beginner, whose mathematical courage must not be damped by premature encounters with difficulties which he cannot surmount. Further, one of the idlest fears that can beset a teacher is the notion that he can possibly make his demonstrations too easy or his explanations too clear. Now, it must, I think, be admitted that in many cases models and experiments may be employed with advantage in aiding a pupil to grasp a demonstration and in developing mathematical insight. Very often, as soon as a clear mind picture of the problem has beeu formed, its solution is obvious. The faculty of visualising a somewhat complicated object without the aid of models can be greatly developed by the judicious use of models, and it shares with mental arithmetic the distinction of being a most valuable mental power, and of being almost entirely uncared for in our educational system. Dr. Todhunter is said to 
have observed that no one who required a model or experiment to enable him to grasp a geometrical or mechanical theorem could ever be a mathematician. I believe that this is perfectly true. But how many of us who are lovers of mathematics would venture to call ourselves mathematicians? If one is not capable of being a mathematician in the high sense of the word, is one therefore to be prohibited from getting at the truth of things as best one can? I may perhaps give a personal reminiscence, which compromises no one but myself. When I went in for the mathematical tripos, I had no real conception of the action of a convex lens. I could have doubtless worked out various questions. But if you had said, "A candle is placed in front of a convex lens, and a real inverted image formed on a screen. The eye is then placed at the point where the image was formed. What will the eye see?" I could not have told you.

But, I may be told, you are asking that proposals for change should be welcomed without telling us what the proposals are. I am not inclined to go very far in the way of specific suggestion at present. The mode of teaching chemistry and physics, and, in particular, the proper extent and aim of a school course in physics, is still far from being settled. I think teachers of mathematics may play a very useful part in the discussion, particularly in encouraging simplicity of method. Apart, however, from the general statement that teaching of geometry, trigonometry, and, in particular, mechanics, has, I submit, much to gain by becoming more concrete, I will venture on one specific suggestion, namely, that for young boys the study of Heat should be replaced by the study of Optics, and that the experimental work in Optics should be under the control of the mathematical staff. The laws of reflection and refraction furnish us with admirable and interesting exercises in practical geometry ; and this work should give definiteness of ideas which will help the subsequent study of aberration, if that is reached at the university stage. Lenses are cheap; rough, but working, models of a sextant, a low-power telescope, an optical level or square and the like, are easily made. I produce a rough model of a sextant, not as being worthy of exhibition-for, if put forward with that intent, it would justly arouse ridicule-but in support of my contention that, with the roughest materials and the simplest tools, a boy of 12 could construct in half an hour a working model capable of measuring angles within a degree, and that a boy of more than 12 could learn a good deal from it. The problem how to make tenth of an inch section paper furnish a scale of degrees gives a little exercise in trigonometry. I attach importance to making rough models with one's own hands. Centering error, index error, error due to the mirrors not being at right angles to the plane of the arc, are very real when, for example, the latter error throws the image right off the second mirror.

I learn from Mr. Fletcher that he has put these views as to the teaching of optics into practice at Liverpool, for some time past, with complete success. If the treaty of alliance Mr. Thwaites proposes is entered into, the teaching of physics will become more mathematical; and here, at any rate, we believe that this will be well. On the other hand, teachers of mathematics will have to lay more stress on the art of stating problems, which is at least as important as the art of solving them. It has been said that hardly any person would fail to solve a strategical problem correctly if it were stated to him correctly, and divested of all irrelevant details. But the task of the commander is, as I suppose, out of the maze of facts, rumours, reports, surmises, and possibilities, to divine what the real problem is; and this is the task of the investigator in most subjects. Mrs. Boole has spoken in a delightful book of the importance of drawing attention, during the early stages of education, to the question whether a particular fact is or is not relevant for a particular purpose. 
I should like to give a couple of concrete instances, one on each side, of the kind of misapprehension which a judicious admixture of theoretical and practical work would tend to prevent. The first I give simply as a legend, not to say a libel. When buffers were first proposed to take up the recoil of a gun on firing they were objected to ; and it is said that their adoption was delayed on the ground that the explosion of the charge communicated a certain definite momentum to the gun, and that the whole of this momentum must be equally communicated, so to speak, to the ground, irrespective of any details of internal construction of the gun carriage. Hence, buffers are useless. Here was a conclusion based upon prenises which were true enough. We, however, see at once that the rate of destruction of momentum is the decisive feature of the problem, and this is just what the buffer alters. If the objector would have jumped from a height of thirty feet, first into a net and then on to a stone pavement, losing the same amount of momentum in each case, he might, either in this world or the next, have reconsidered his argument.

On the other hand, in remonstrating with a student for producing some entirely new views on specific gravity, I once said, "But you must have often done this experimentally at school." The answer was : "Yes, sir : but we always had the formula given us, and only had to think about the weights." I do not much, if at all, object to his having the formula given him, but I do object to his only thinking about the weights. We must not forget that, while experiment is good, the discoverer thinks before he experiments as well as after. Here, again, I think teachers of mathematics may exert a beneficial influence. Some people fear that that the fusion of physics and mathematics in public school teaching may be like the fusion of the tiger and the lamb. But I hope I have shown that the high contracting parties will meet on a footing of equality, and should both benefit equally. An apprehension is sometimes expressed as to the cost of laboratories and appliances for teaching physics. I am happy to think that many people whose opinion on a question of science is of real weight, agree with me in thinking that we have had far too much in the past of the "instrument on polished mahogany base, with all brass parts richly lacquered," for demonstrating that a weight hung up by a string will oscillate to and fro if disturbed from its position of equilibrium. Home-made apparatus-cardboard, seccotine and scissors, sixpenny lenses in cardboard tubes, paper scales, levers and pulleys made in the school workshops-are what we want. The fact is often lost sight of how rough, comparatively speaking, were some of the methods and results of the great pioneers.

Mankind may be divided roughly into two classes: those who understand their job and those who do not, generally because they do not know what understanding a subject means. Our first object as teachers is to teach people what understanding means, in order that in after life they may try to belong to the former class, be their job what it may.

I have attempted to put before you the arguments which have convinced me that a judicious admixture of mathematics and physics will aid us more powerfully than stronger separate doses of each to effect our object.

C. S. JACKSON.

\section{ON THE AXIOMS AND POSTULATES EMPLOYED IN THE ELEMENTARY PLANE CONSTRUCTIONS.}

By the elementary plane constructions we mean the bisection of angles and segments of lines and the drawing of perpendiculars. The constructions given below are extremely simple, and it is very possible that some or all of them have been given before; but they seem to be of sufficient interest to 